\title{
Justicia ambiental y jurisprudencia constitucional: El caso de las desigualdades ambientales en el Páramo de Pisba
}

\author{
Environmental Justice and Constitutional Jurisprudence: The Case of \\ Environmental Inequalities in the Pisba Paramo
}

Víctor Manuel MonCADA PRIETO ${ }^{1}$

Oscar Andrés LÓPEZ CORTÉS²

\begin{abstract}
Resumen: Este artículo analiza las nociones de justicia ambiental y participación ciudadana en materia ambiental en Colombia con base en las posiciones jurisprudenciales fijadas por la Corte Constitucional Colombiana y los debates académicos al respecto. Teniendo como eje de referencia las discusiones: sociales, políticas y ambientales que sobre los ecosistemas paramunos en Colombia se han tenido, tomamos como ejemplo la afectación minera al páramo de Pisba y a las personas que habitan los municipios que hacen parte del páramo y de aquellos que le son circundantes.
\end{abstract}

Palabras clave: Páramo, Justicia ambiental, Jurisprudencia, Participación ambiental

\begin{abstract}
This article analyzes the ideas of environmental justice and citizen participation in environmental topics in Colombia based on the case law positions developed by the Constitutional Court of Colombia and academic debates. Taking as reference: social, politics and environmental reflections about paramunos ecosystems, that in Colombia have been given, we take as an example the mining harm to Pisba Paramo and to people who habits municipalities who belongs to the paramo and around.
\end{abstract}

Keywords: Paramo, Environmental Justice, Jurisprudence, Environmental Participation

\footnotetext{
${ }^{1}$ Abogado de la Universidad Libre, Candidato a magister en geografía de la Universidad Nacional, https://orcid.org/0000-00018809-2672. Investigador Auxiliar de la Universidad Libre. Bogotá- Colombia. Correo electrónico: manuellmonk@gmail.com ${ }^{2}$ Abogado de la Universidad Nacional, Magister en Derecho de la Universidad Nacional, Doctor en Antropología de la Universidad del Cauca, Profesor de la Universidad Libre, sede Bogotá, https://orcid.org/0000-0002-7589-7233. Bogotá-Colombia. Correo: oscarandreslopezcortes@gmail.com
} 


\section{Introducción}

La Constitución colombiana de $1991^{3}$ promueve el modelo de democracia participativa ${ }^{4}$. En ese marco, el deber de garantizar un ambiente sano recae no solo sobre el Estado y su entramado de instituciones y normas conocido como el Sistema Nacional Ambiental (SINA), sino sobre la ciudadanía en general. Sin embargo, es el modelo de democracia representativa el que en la práctica domina la toma de decisiones en materia ambiental. Las consecuencias de este modelo resultan contrarias a los valores propios de una constitución ecológica, como la ha definido la Corte Constitucional a través de su jurisprudencia, en tanto ha priorizado un modelo de desarrollo basado en los intereses de los inversionistas antes que en los derechos de la naturaleza y de las comunidades.

Pese a la ineficacia del modelo representativo, la organización y movilización de actores sociales como los pueblos indígenas, afros, campesinos y ambientalistas, en pro de una nueva agenda de reivindicaciones por los derechos ambientales, ha tenido eco en algunas instituciones del Estado, como la rama judicial y la Defensoría del Pueblo. Incluso, se ha desarrollado en Colombia, como en otros lugares del mundo, la tesis jurisprudencial que reconoce a la naturaleza como sujeto de derecho. Al caso del río Atrato, se suman el de la Amazonía, el páramo de Pisba, el río Cauca, entre otros ecosistemas que han sido reconocidos como sujetos de derecho, superando así los paradigmas del antropocentrismo y el biocentrismo, para acoger la perspectiva ecocéntrica. Pero los avances teóricos de la jurisprudencia no han detenido la degradación a la que sigue sujeta la naturaleza, como lo demuestra la situación del río Atrato, el incremento de la deforestación en la Amazonía, la crisis generada por Hidrotuango o la concesión irregular de licencias de explotación a la empresa Hunza Coal en zonas protegidas que hacen parte del páramo de Pisba.

En muchos de estos territorios, entendidos como "espacios apropiados de manera concreta y abstracta por uno o varios sujetos sociales en función de la realización de sus intencionalidades territoriales y sociales" 5 , se generan conflictos que involucran a poblaciones campesinas, que, a diferencia de las poblaciones indígenas y afro, no gozan del mismo reconocimiento normativo como sujetos colectivos de derechos. Apenas en 2018 la ONU acogió la "Declaración sobre los Derechos de los Campesinos y de Otras Personas que Trabajan en las Zonas Rurales" adoptada el

\footnotetext{
${ }^{3}$ Asamblea Nacional Constituyente (1991).

${ }^{4}$ Corte Constitucional de Colombia, sentencia T-361 de (2017c) F.J. 12.4.1, mayo 30 de 2017.

${ }^{5}$ Sánchez (2014), p. 352.
} 
28 de septiembre por el Consejo de Derechos Humanos y aprobada el 19 de noviembre por la Asamblea General a través de la resolución A/C.3/73/L.306. Si bien las declaraciones no tienen el carácter vinculante de un convenio internacional, diferencia que no se discutirá aquí en detalle por no ser el objeto de este artículo, cabe señalar que mediante este instrumento se reconoce a las poblaciones campesinas y trabajadores del campo como actores diferenciales con derechos propios para la defensa de sus formas de vida y hábitat. La votación de la Declaración en el organismo internacional reveló la tensión profunda que existe entre los derechos de los pueblos campesinos y los intereses del capital transnacional: de 183 países 54, entre esos Colombia, se abstuvieron de votar a favor de los derechos de los pueblos campesinos, 8 se manifestaron en contra.

Pese a las pocas garantías normativas, las comunidades campesinas no cesan de reclamar espacios de intervención decisivos para su futuro, entre otros, más y mejores mecanismos de participación en materia ambiental. Estos espacios son disputados por las empresas dedicadas a la explotación de recursos naturales, políticas muy presentes en las agendas gubernamentales de varios países de América Latina en los cuales se han entronizado las prácticas extractivistas 7 .

A partir de allí surge la pregunta que guía la discusión de este artículo: ¿qué diferencias y semejanzas se encuentran entre la noción de justicia ambiental que acoge la jurisprudencia constitucional en materia ambiental y la que es incorporada en las prácticas de un movimiento campesino ambiental colombiano? El objetivo general de este artículo es mostrar que tan cerca o tan lejos puede estar la jurisprudencia de la Corte Constitucional en materia ambiental de las prácticas desarrolladas por el movimiento campesino en Colombia. Como objetivos específicos se pueden encontrar, en primer lugar, el de reconstruir las nociones y elementos de la justicia ambiental tal y como se encuentran en la literatura más reciente en la materia; el segundo objetivo específico es el de ofrecer una aproximación al concepto de justicia ambiental presente en la jurisprudencia de la Corte Constitucional colombiana. Como tercer objetivo específico se encuentra el de exponer un caso de estudio que evidencia las tensiones entre las nociones de justicia ambiental del principal órgano judicial constitucional de Colombia y un movimiento campesino del mismo país.

${ }^{6}$ Declaración sobre los derechos de los campesinos y de otras personas que trabajan en las zonas rurales, 28 noviembre 28 de 2018.

${ }^{7}$ Göbel y Ulloa (2014), pp. 15-33. 
Para logra los objetivos trazados este artículo esta compuesto de tres partes: en la primera se presenta un recuento de las nociones y elementos de la justicia ambiental, herramientas teóricas que servirán para analizar críticamente la jurisprudencia constitucional en la segunda parte, donde se abordarán las formas como la jurisprudencia constitucional colombiana ha retomado la noción de justicia ambiental; como las decisiones judiciales abarcan un amplio espectro, el análisis se limitará a dos dimensiones recurrentes en la discusión judicial en materia de participación ambiental: la división de competencias entre los entes territoriales y el orden nacional, y la participación comunitaria en los procesos de delimitación de páramos. La tercera parte del artículo expone con detalle un caso concreto en el cual se presentan desigualdades ambientales, en este se tomarán elementos teóricos de la primera parte y jurisprudenciales de la segunda, para el análisis del caso.

\section{Discusiones alrededor de la justicia ambiental}

La justicia ambiental tiene sus inicios en las denuncias de las poblaciones negras frente a las desigualdades ambientales a las que se veían sometidas, lo que posteriormente sería considerado el origen del término "racismo ambiental" acuñado por Benjamín Chavis en 19878. Campos et al..$^{9}$ y Jessup ${ }^{10}$ coinciden en situar el surgimiento de la noción de justicia ambiental en las luchas de los años setenta del Siglo XX promovidas por poblaciones negras en Carolina del Norte en contra de los vertederos de tóxicos que se construyeron en sus territorios ${ }^{11}$. Estas comunidades no se veían representadas en las reivindicaciones de los colectivos ambientalistas, los cuales ignoraban la situación de estas comunidades marginadas, así como la contaminación ambiental de sus entornos de trabajo, sus hogares y el daño a su salud ${ }^{12}$.

El reclamo de esas repercutió en otros grupos poblacionales (indígenas, hispanas, obreras, y ecologistas) de diferentes partes del mundo ${ }^{13}$; poblaciones que reconocieron las injusticias ambientales en sus territorios sin limitarse a las consignas propuestas por el ambientalismo y reivindicaron las desigualdades generadas por daños al ambiente en el transporte, la vivienda, la distribución de recursos, el uso de la tierra, la salud y la construcción de plantas nucleares, hidroeléctricas, entre otros ${ }^{14}$. Estos movimientos provocaron una comprensión ética de los

\footnotetext{
${ }^{8}$ Barbalace (2001), párr. 2.

${ }^{9}$ Campos et al. (2015), p. 61.

10 Jessup (2018), p. 51.

${ }^{11}$ Arriaga (2010), p. 07 ; Agyeman et al. (2002), p. 81 ; Freudenberg y Steinsapir (1991), p. 238 y Valenzuela (2018), p. 177.

12 Freudenberg y Steinsapir (1991), p. 238; Dichiro (1999), pp.106-109.

13 Campos et al. (2015), pp. 60-64.

${ }^{14}$ Ramírez et al. (2015), pp. 228-231.
} 
entornos naturales como fines en sí mismos ${ }^{1516}$. Al respecto, se puede establecer una conexión teórica entre el movimiento de justicia ambiental y el paradigma ecocéntrico, en el cual al defensa de la naturaleza se da como un fin en sí mismo y no como un medio para el bienestar humano.

Para Martínez-Alier ${ }^{17}$ el inicio de estos movimientos tuvo lugar en las naciones industrializadas, pero también su paralelo en los países no industrializados, a lo que él denomina como "ecología de los pobres". Formas de lucha y resistencia en la que grupos locales se enfrentan, contra toda posibilidad, a gobiernos, empresas nacionales y multinacionales, entre otros actores que generan y profundizan las desigualdades. No obstante, estas intervenciones hallan respuestas por parte de personas que se organizan en defensa de su territorio, pese a encontrarse en situaciones de pobreza y abandono estatal ${ }^{18}$.

Bellmont ${ }^{19}$ indica que estas desigualdades surgen en razón al poder político y económico que conservan algunos actores, el cual se materializa con lógicas idénticas en diferentes bloques geográficos. Esto reproduce las posiciones económicas y políticas hegemónicas a favor de algunos países o regiones, y en su lugar histórico como beneficiarios de los procesos y recursos que se surten y se extraen de otros entornos ambientales. El análisis de Rees ${ }^{20}$, sobre el consumo ambiental de los países con PIB per cápita superior, evidencian los déficits soportados por los habitantes de aquellos Estados con menor PIB per cápita, quienes sostienen el consumo de los primeros. En el mismo sentido está el trabajo de Lessenich, quien demuestra como países como Alemania, Japón o Estados Unidos, se benefician del costo ambiental asumido en países como Ghana, Colombia o Malasia. Los bloques geográficos privilegiados económicamente, consideran que no son responsables de los efectos negativos de la explotación, como la contaminación, la destrucción y el desarrollo de prácticas extractivas en entornos ambientales externos. Esto ha conminado a países con menor capacidad de presión política y económica a asumir las cargas ambientales, sin recibir una compensación proporcional a la pérdida de sus recursos naturales.

\footnotetext{
${ }^{15}$ Riechmann (2003), pp. 107-115.

${ }^{16}$ Martínez-Alier (2002).

17 Ídem.

${ }^{18}$ Martínez-Alier (2008), pp.13-15.

${ }^{19}$ Bellmont (2012), pp. 31-36.

${ }^{20}$ Rees (2009), pp. 15-19.
} 
A este proceso Stephan Lessenich ${ }^{21}$ lo ha denominado sociedad de la externalización, en una analítica que retoma la justicia ambiental incluyendo la relación inescindible entre cultura y naturaleza vista desde el lugar privilegiado de un ciudadano alemán de clase media:

(...) vivimos a expensas de otros, y en última instancia a costa de sus vidas. Al margen de lo que el liberalismo económico pueda explicarnos a nosotros y a los demás, la productividad no es un milagro, el progreso no es universal, las reducidas oportunidades vitales en las periferias del capitalismo de bienestar no son producto de la casualidad. La productividad de nuestras economías, que ya por sí misma es asombrosa pero que también asombrosamente crece de modo constante, se basa decisivamente en la explotación sistemática de los recursos materiales y de la aplicación de trabajo físico -de hombre y naturaleza- en otras partes del mundo ${ }^{22}$.

Los movimientos de justicia ambiental, pese a sus diferencias con otros movimientos ambientalistas, hoy en día se encuentran más articulados en la lucha por corregir las inequidades e injusticias sociales que padecen determinados grupos poblaciones en contextos atravesados por lo ambiental23, superando así parte de las tensiones provocadas en su inicio.

En cuanto a la definición de justicia ambiental no se encuentra en la literatura un concepto unívoco al respecto, por cuanto no se puede otorgar valor idéntico a todos sus elementos. Un elemento común en las definiciones es que los alcances de la justicia ambiental no se limitan a la distribución equitativa de los beneficios y las cargas perjudiciales producto de la intervención ambiental; por el contrario, las definiciones coinciden en que a través de ella se busca eliminar todas las cargas ambientales negativas que puedan subsistir para las poblaciones ${ }^{24}$. La justicia ambiental pretende la erradicación de las desigualdades sin consideración del género, la raza, la etnia y la clase; se centra en las realidades rurales y urbanas, siendo estas últimas fuentes significativa para los debates contemporáneos; vela por alcanzar entornos ambientales en donde el ser humano pueda disfrutar de salud, seguridad y una calidad de vida digna 25 .

Otro elemento común en las definiciones es que su análisis parte de las desigualdades ambientales presentes, atendiendo a los procesos, los actores e instituciones que intervienen en ellos, convirtiendo la aproximación histórica en una clave para comprender y abordar los espacios de injusticia ambiental. Al Indagar por la manera como se producen tales espacios, los

\footnotetext{
${ }^{21}$ Lessenich (2019).

${ }^{22}$ Lessenich (2019), p. 192.

${ }^{23}$ Freudenberg y Steinsapir (1991), p. 243.

${ }^{24}$ Agyeman et al. (2002), p. 82.

${ }^{25}$ Campos et al. (2015), p. 60.
} 
objetivos que se proponen y los que consiguen, es posible desarrollar en mejor forma las discusiones sobre justicia ambiental en las diferentes realidades políticas y sociales ${ }^{26}$.

Una perspectiva geográfica de las justicias ambientales es necesaria por cuanto las desigualdades tienen arraigo en contextos y espacios determinados, en los que prevalecen escenarios de desigualdad social, por razones de género, raza, etnia y clase, entre otras categorías $^{27}$. La escala forma parte de las perspectivas que consideran la justicia ambiental, dado que logra dimensionar procesos nacionales y globales, así como las redes a partir de las cuales se forman conexiones que determinan los entornos naturales locales.

El concepto de justicia ambiental dialoga con el de justicia espacial28, el cual parte de una idea del espacio como construcción social y política, debate ampliamente desarrollado en la teoría geográfica ${ }^{29}$. Esta idea permite comprender que los espacios están construidos y vividos con base en sentidos políticos, sociales, simbólicos, culturales, entre otros, lo cual permite reconocer que la condición del agente que interviene determina un dosier mayor o menor de oportunidades. Esto es relevante en términos de justicia espacial, por cuanto los diferentes actores son conscientes de que las posibilidades de vida en una u otra espacialidad difieren. No obstante, la distribución espacial que se genera no responde al ánimo de los individuos o de las poblaciones, sino a estructuras políticas y económicas que conminan a los menos favorecidos a ocupar los espacios marginales.

Los debates sobre justicia ambiental han cuestionado las formas como se construyen los discursos políticos y académicos en materia ambiental ${ }^{30}$, al evidenciar el rol del conocimiento experto en la toma de decisiones que perjudican a los más marginales. En lo político, se ha desvelado cómo los diferentes dispositivos de normalización de las prácticas han permitido y fomentado una distribución del espacio atravesada por el poder, en la que la clase y la raza se imponen a nivel espacial y ambiental.

La noción de justicia ambiental no es el resultado de un ejercicio acabado, dado que tiene desarrollos particulares en cada región, acorde a los procesos asociados a los contextos y lugares. Las diferencias en los debates también pueden obedecer a las variaciones legislativas propias de cada Estado. Por ejemplo, en algunas regiones de Chile una de las discusiones

${ }^{26}$ Cotton (2017), pp. 3-4.

27 Ídem, p. 3.

${ }^{28}$ Campos et al. (2015), pp. 60-65; Bellmont (2012), pp. 24-28.

${ }^{29}$ Lefebvre (2013); Soja (1996).

${ }^{30}$ Carruthers (2008), p. 50. 
recurrentes atañe al derecho de uso a perpetuidad legal del agua, el cual se encuentra acaparado por grandes superficies empresariales que marginan de su uso y aprovechamiento a determinas comunidades ${ }^{31}$. Mientras que en Colombia, algunas de las discusiones sobre el agua, no recaen sobre la propiedad, al ser pública por ley, sino sobre la distribución y el acceso a las fuentes hídricas.

En Estados Unidos los debates sobre justicia ambiental generan desencuentros entre el ambientalismo que busca proteger la naturaleza dejando afuera a los seres humanos, en cuanto parte de una división excluyente entre humanidad y naturaleza, y los movimientos de justicia ambiental que modifican la noción de ambiente, al considerar que este incluye también sus espacios de interacción, como el trabajo, los lugares de recreación y la vivienda, entre otros.

Los movimientos de justicia ambiental estadounidense han logrado amplio reconocimiento, lo cual ha derivado en informes ${ }^{32}$ y la creación normativas e instituciones como la Oficina de Justicia Ambiental. A través de estas se pretende enfrentar las injusticias ambientales causantes de efectos negativos en las poblaciones marginales, facilitando la participación de las comunidades y al Estado modificar las maneras de intervención, con el objeto de distribuir equitativamente las cargas ambientales negativas entre todos los sectores de la población.

En Europa no hay noción de justicia ambiental materializada completamente. Los trabajos en la materia enfatizan las desigualdades basadas en las condiciones de clase. Con la creación y aplicación del convenio de Aarhus (1998) ${ }^{33}$ se han generado garantías para que las comunidades intervengan en materias ambientales relacionadas con el acceso a la información, la participación en la toma decisiones y mecanismos de justicia ${ }^{34}$.

En Latinoamérica las limitaciones a los procesos de justicia ambiental se manifiestan principalmente en los obstáculos para acceder a información completa y de calidad. Esto se debe a que los Estados carecen de políticas claras y fuertes al respecto o no suministran información y las empresas se legitiman en el actuar estatal para abstenerse de brindar información. La incapacidad económica para desarrollar o contratar estudios que ilustren, y de ser el caso cuestionen, los proyectos e intervenciones ambientales, así como la ausencia de diagnósticos

\footnotetext{
${ }^{31}$ Romero (2009), p. 08.

${ }^{32}$ Commission for Racial Justice (1987).

${ }^{33}$ Convenio de Aarhus (1998).

${ }^{34}$ Bellmont (2012), pp. 29-30; Arriaga (2010), pp. 3-6.
} 
acertados y confiables en material ambiental, son otras causas que operan en contra de la justicia ambiental 35 .

El limitado acceso a la información científica representa otro obstáculo para avanzar en los estudios sobre justicia ambiental, lo cual obedece a la escasa producción académica local. Otra limitación lo impone el hecho de que la producción académica mayoritariamente se encuentran en inglés. Finalmente, la apatía de los gobiernos en materia de protección de los entornos naturales es otra dificultad que impide materializar procesos de justicia ambiental en Latinoamérica.

Los lugares donde más se presentan injusticias ambientales se caracterizan por el bajo uso que sus habitantes hacen de los procesos democráticos. Pese a que la explotación de los entornos naturales genera grandes dividendos por concepto de compensaciones o regalías, no se cuenta con formas efectivas para controlar las actuaciones de las empresas ni de los gobiernos locales. Un ejemplo de esto se presenta en la Guajira y Casanare, departamentos de Colombia que pese a generar millones de dólares a través de la extracción del carbón y el petróleo, la baja inversión social, la corrupción y la desidia administrativa, impiden gozar a sus habitantes de derechos sociales que deberían estar garantizados con los recursos derivados de las regalías.

En algunos países, no existen las herramientas legales para exigir la protección de las poblaciones afectadas por las desigualdades ambientales. En Colombia ${ }^{36}$ se presenta una paradoja escasez y abundancia en este sentido, dado que hay exceso de normas fruto de trasplantes jurídicos para la protección de los entornos ambientales y de las personas, pero sin posibilidades de aplicación material.

El último elemento en materia de justicia ambiental común a la mayor parte de Latinoamérica, y muy presente en Colombia, es la violencia. Esta ha supuesto limitaciones serias para el desarrollo de ejercicios de justicia ambiental, dado que impide el avance de las investigaciones judiciales sobre las desigualdades. Entre las causas más comunes se encuentra el hecho de que los procesos de injusticia ambiental se relacionan con un entramado constituido por múltiples formas de violencia, en ocasiones ejercidas gracias a la omisión de las autoridades estatales, e incluso con su colaboración. Como ha ocurrido en casos de desplazamiento forzado de comunidades con arraigo cultural y social en espacios donde contaban con garantías para su

\footnotetext{
${ }^{35}$ Carruthers (2008), pp. 3-4.

${ }^{36}$ Mesa (2010) apaud: Bellmont (2012), pp. 101-102.
} 
seguridad alimentaria e hídrica, que les fueron arrebatados para la creación de proyectos mineros, forestales, energéticos, entre otros. Entre los casos más representativos se encuentran los de la minería de oro en Cajamarca (Tolima) con el proyecto La Colosa, la tercera minera a cielo abierto de explotación de oro más grande en Latinoamérica ${ }^{37}$; la minería en Marmato, departamento de Caldas ${ }^{38}$; la agroindustria en Montes de María ${ }^{39}$, la hidroeléctrica Ituango, en donde se desplazaron poblaciones enteras de sus territorios ${ }^{40}$; los cultivos de palma de aceite en la altillanura oriental ${ }^{41}$, entre muchos otros.

\section{Posición jurisprudencial en materia de participación ambiental}

La Corte Constitucional ha generado precedentes importantes en materia ambiental ${ }^{42}$, a partir de los cuales se han dinamizado las relaciones entre la sociedad civil, el Estado y las empresas nacionales y multinacionales. La jurisprudencia ha promovido esta dinámica a partir de la reconfiguración de restricciones previstas en la ley o por el reconocimiento de derechos en la materia derivados directamente de la Constitución o de las normas internacionales.

La Corte Constitucional ha tomado decisiones en defensa de actores sociales tradicionalmente marginados de los debates y los procesos de toma de decisión sobre los territorios por ellos habitados. Entre los beneficiados de estas decisiones se encuentran las poblaciones campesinas y las comunidades locales, quienes han asumido históricamente las consecuencias de las decisiones que, sobre sus territorios, sus recursos ambientales y su soberanía alimentaria, toman las empresas y algunos entes gubernamentales.

Alrededor de los procesos de participación en la toma de decisiones que afectan entornos ambientales y del cuestionamiento a propósito de si a las comunidades locales y campesinas les está permitido participar en el proceso de planeación, se ha debatido extensamente. Las primeras sentencias reconocieron de forma dubitativa el derecho de las comunidades a participar en las políticas ambientales. Posteriormente las sentencias: C-535 de (1996a)³, C-593

\footnotetext{
${ }^{37}$ Sánchez (2014); Méndez (2013).

${ }^{38}$ Sabogal (2013).

39 Ojeda (2016).

${ }^{40}$ Cañola y Palacio (2019); Torres (2013).

${ }^{41}$ Rojas (2016); Piñeros (2016).

${ }^{42}$ Corte Constitucional de Colombia, sentencias T-411 de (1992), F.J. 2.2-3.2, junio 17 de 1992; C-293 de (2002), F.J. 3.-4.3, abril 23

de 2002; T-622 de (2016d), F.J. 5.1-5.21, noviembre 10 de 2016.

${ }^{43}$ Corte Constitucional de Colombia, sentencia C-535 de (1996a), F.J. 31-33, octubre 16 de 1996.
} 
de $(1995)^{44}$ y T-574 de (1996b) ${ }^{45}$, crearon una línea de reconocimiento entorno al derecho de las poblaciones locales de participar en las decisiones que afecten sus recursos naturales, recalcando el deber del Estado de garantizar espacios de participación en materia ambiental.

En el año 2012 se avanzó en el reconocimiento del derecho a la participación de las comunidades mencionadas. La Corte Constitucional fijó entonces el deber estatal de crear espacios obligatorios y apropiados para la participación en materia ambiental, así como el diseño de medidas de compensación y corrección adecuadas a la magnitud del proyecto industrial (en este caso un proyecto pesquero) a implementar; medidas que deben surgir de procesos de concertación con las comunidades afectadas (T-348 de 2012) ${ }^{46}$. Respecto a los proyectos con implicaciones ambientales, la Corte Constitucional enfatizó el deber estatal de identificar las posibles afectaciones a los actores locales, para así facilitar su participación (T-135 de (2013) ${ }^{47}$.

En el año (2014b) ${ }^{48}$ la Corte Constitucional sentó un precedente que modificó la forma como en lo sucesivo se desarrollaría el debate de la participación en materia ambiental, al reconocer la noción de justicia ambiental como elemento clave para abordar la participación ciudadana en esta materia. Al respecto, consideró que las intervenciones estatales que alteran el territorio y sus recursos implican cargas y beneficios al conglomerado social intervenido, lo cual exige que la administración distribuya equitativamente los costos y los beneficios. Al distribuir las cargas, el Estado debe tener en cuenta el origen étnico, el género, el nivel de instrucción y la condición de clase, entre otros factores. En estos términos, la jurisprudencia exhortó a la administración a asumir el enfoque interseccional y a identificar la manera como determinadas situaciones conminan a ciertas poblaciones a soportar desigualdades que afectan el disfrute real y efectivo de sus derechos y su capacidad para llevar una vida digna; sin ese enfoque, las decisiones públicas profundizarían las desigualdades ${ }^{49}$.

Según la Corte Constitucional50, los escenarios de injusticia ambiental presuponen una distribución inequitativa de cargas y beneficios que conmina a determinados grupos poblacionales al deterioro de sus condiciones de vida. Si esta realidad es ignorada por quienes toman decisiones en procesos de licenciamiento ambiental, la injusticia aumenta. El resultado

\footnotetext{
${ }^{44}$ Corte Constitucional de Colombia, sentencia C-593 de (1995), F.J. C, diciembre 07 de 1995.

${ }^{45}$ Corte Constitucional de Colombia, sentencia T-574 de (1996b), F.J. 2 y caso concreto párr. 05 , octubre 29 de 1996.

${ }^{46}$ Corte Constitucional de Colombia, sentencia T-348 de (2012), F. J. 2.3.2-2.3.2.6 mayo 15 de 2012.

47 Corte Constitucional de Colombia, sentencia T-135 de (2013), F.J. 3, marzo 13 de 2013.

${ }^{48}$ Corte Constitucional de Colombia, sentencia T-294 de (2014b), F.J. 12-35, mayo 22 de 2014.

${ }^{49}$ Cruells (2015), pp. 33-79.

${ }^{50}$ Corte Constitucional de Colombia, sentencia T-294 de (2014b), F.J. 12-35, mayo 22 de 2014.
} 
de las operaciones industriales, comerciales o la ejecución de proyectos ambientales, pueden dejar al margen a poblaciones que han habitado los territorios desde tiempos antiquísimos. Las discusiones entorno a la justicia ambiental, requieren de la participación de las comunidades y de que sus voces sean tenidas en cuenta en la toma de decisiones.

La noción de justicia ambiental, expresó la Corte, está integrada por dos elementos: el reparto equitativo de cargas y beneficios fundado en el principio constitucional de equidad ambiental; y de otro lado, una demanda de justicia participativa, principalmente de aquellos que se consideran o son efectivamente afectados. El primero de estos elementos se basa en dos artículos constitucionales: 79 “participación ciudadana en materia ambiental”, y 13 “derecho a la igualdad”. De la articulación entre estas normas se derivan tres consecuencias: la obligación estatal de proteger el acceso equitativo para todas las personas a los bienes ambientales, el reparto equitativo de las cargas contaminantes y la exigencia de mayor protección para los grupos sociales más desprotegidos. La participación ciudadana se fundamenta en los artículos constitucionales número: 2 "fines esenciales Estado", 40 "derecho a la participación ciudadana", 79 "participación ciudadana en materia ambiental"; normativa que exige al Estado asegurar la participación ciudadana en las decisiones que les afectan en materia ambiental.

El precedente que adopta la justicia ambiental, como criterio clave para sustentar la participación de actores locales, fue reiterado y ampliado en sentencias que abordaron diversos problemas jurídicos en la materia. Uno de ellos es el caso de un grupo de pescadores artesanales en la playa Bahía Gayraca ${ }^{51}$, quienes se vieron afectados debido a que la zona donde ejercían sus actividades fue anexada al Parque Nacional Tayrona, mediante acto expedido por la Unidad Administrativa del Sistema de Parques Nacionales Naturales. La Corte señaló que, aunque los procesos de delimitación obedecen al deber constitucional de proteger las zonas estratégicas a nivel ambiental, no por esto se puede pretermitir el diálogo efectivo con todas las poblaciones que resulten afectadas por las decisiones de los entes públicos. Los criterios de justicia ambiental establecidos son de mayor interés si se comprende que las decisiones pueden afectar a grupos poblacionales vulnerables, como aquellos que derivan de la pesca artesanal su único sustento.

El derecho a la participación de las comunidades en materia ambiental se precisó en decisiones posteriores: sentencias T-660 de (2015b)52, C-389 de (2016b) ${ }^{53}$, SU-133 de

\footnotetext{
${ }^{51}$ Corte Constitucional de Colombia, sentencia T-606 de (2015a), F.J. 5.3.2 y 7.3 (i), septiembre 21 de 2015.

52 Corte Constitucional de Colombia, sentencia T-660 de (2015b), 3.4.1.2 y 3.4.1.5, octubre 23 de 2015.

${ }^{53}$ Corte Constitucional de Colombia, sentencia C-389 de (2016b), F.J. 67. y 3., julio 27 de 2016.
} 
(2017a) ${ }^{54}$. En estas se considera que los espacios de participación deberán tener la capacidad de generar diagnósticos acertados y concertaciones mínimas entre los grupos sociales interesados, quienes son los conocedores directos de los territorios que se intervienen. Además, por parte del Estado, recae el deber de realizar los estudios de las condiciones socioeconómicas de las poblaciones que pueden resultar afectadas (2015b).

El precedente constitucional reconoce que un ejercicio de participación ciudadana efectiva y real en materia ambiental, redundará en un beneficio doble de las actuaciones estatales, en cuanto permite materializar la democracia participativa y le reconoce seguridad jurídica a las concesiones que intervienen el territorio (2017a) ${ }^{55}$. Además, las reglas establecidas a través del precedente han sido calificadas como vinculantes, por lo que se puede hablar de un desconocimiento del derecho de participación de las comunidades en materia ambiental en aquellos casos en los cuales no se han respetado los criterios fijados por la jurisprudencia de la Corte Constitucional (2017b) 56 .

\section{Entes territoriales y el orden nacional}

La Corte Constitucional (2014a) ${ }^{57}$ amplió el debate de la participación en materia ambiental, al complejizar la potestad que tiene el nivel central, encargado de definir la destinación y uso del subsuelo, pues aunque tal potestad recaiga en el orden central, se dijo entonces que esta prerrogativa no puede ejercerse de manera absoluta, al punto de silenciar el derecho a la participación de las comunidades locales y sus órganos de representación. Son los actores sociales, especialmente los que se encuentran en los territorios intervenidos por los proyectos económicos, quienes soportarán de manera directa las consecuencias de la intervención y por ende a quienes se les deberá garantizar la participación efectiva y eficaz (2014a, 2016a) ${ }^{58}$.

El debate sobre la potestad entre el orden central y territorial para intervenir y aprovechar el subsuelo, y por consecuencia la necesaria intervención en el suelo, se mantuvo en el sentido planteado hasta el año (2016c) ${ }^{59}$. Entonces, la jurisprudencia reforzó la potestad de los entes territoriales para oponerse a la intervención ejercida por el nivel nacional sobre los suelos de

\footnotetext{
${ }^{54}$ Corte Constitucional de Colombia, sentencia SU-133 de (2017a), F.J.73, 101, 175 y 188, febrero 28 de 2017.

55 Ídem, F.J. 101. y 222.

${ }^{56}$ Corte Constitucional de Colombia, sentencia SU-217 de (2017b), F.J. 250 , abril 18 de 2017.

${ }^{57}$ Corte Constitucional de Colombia, sentencia C-123 de (2014a), marzo 05 de 1014.

${ }^{58}$ Corte Constitucional de Colombia, sentencias: C-123 de (2014a), F.J. 5.4., marzo 05 de 2014; C-035 de (2016a), F.J. 30 y 36, febrero

08 de 2016.

${ }^{59}$ Corte Constitucional de Colombia, sentencia T-445 de (2016c), F.J 15.3.1-15.3.1.4, agosto 19 de 2016.
} 
municipios y departamentos. Esa decisión respaldó a las comunidades locales, lo que produjo un incremento significativo de acuerdos municipales y consultas populares, a través de las cuales se sometieron a votación popular decisiones entorno a la explotación minera y de hidrocarburos. Al parecer esta aplicación de la justicia ambiental incomodó a los empresarios de la minería, como lo dejó ver la declaración de Santiago Ángel Urdinola, entonces presidente de la Asociación Colombiana de Minería, al afirmar que aproximadamente 135 municipios hicieron uso de alguna de estas herramientas legales con el objeto de detener o impedir explotaciones en el subsuelo60.

Luego de eso, la Corte Constitucional cambió su posición en esta materia61. En un precedente que otorgó al nivel central la potestad constitucional para decidir sobre la explotación del subsuelo, relegó los acuerdos entre el Gobierno Nacional y los entes territoriales a una relación de coordinación y concurrencia relativa a la intervención del subsuelo. Además, eliminó la posibilidad de que a través de consultas populares se decidiera sobre la explotación del subsuelo, al considerar que esta competencia recaía de manera exclusiva en el nivel central.

En este punto podemos apreciar un retroceso en la jurisprudencia: una forma de lo que podría denominarse regresividad de la doctrina constitucional en materia de definición de competencias entre el nivel central y el local y la participación de las comunidades locales en el manejo del suelo y el subsuelo. Esta regresión afecta negativamente la progresividad de los derechos ambientales garantizados en la en el orden superior y marca un precedente que modifica el concepto de constitución ecológica que había desarrollado el máximo tribunal en esta materia. Por último, no deja de ser paradójico que esto se haya desarrollado precisamente en la misma época que esa corporación judicial asumió la tesis de la naturaleza como sujeto de derechos, la cual sin duda es importante en la dogmática constitucional, pero se opaca esta decisión deja la idea en el aire que la tesis dela SU-095 de 2018 tiene una perspectiva de la naturaleza prístina y deshabitada, sin presencia humana, lo cual no se compadece con la perspectiva ecocéntrica desarrollada desde la sentencia del Río Atrato, para la cual la naturaleza es un todo del cual hace parte la especie humana como otra más.

${ }^{60}$ Diario Digital La Piragua (2018).

${ }^{61}$ Corte Constitucional de Colombia, sentencia SU-095 de (2018), F.J. 3.2, octubre 11 de 2018. 


\section{Participación comunitaria en el proceso de delimitación del páramo de Pisba}

Antes de entrar en el análisis detallado del caso del páramo de Pisba es importante reconstruir la jurisprudencia constitucional relacionada con la delimitación de páramos en Colombia y la participación de las comunidades en el proceso. La sentencia T-361 de (2017c) ${ }^{62}$ es la base de las líneas desarrolladas en la materia. En esa oportunidad la Corte abordó la discusión acerca de la obligación a cargo del Ministerio del Ambiente y Desarrollo Sostenible (MADS), de garantizar la participación de las comunidades locales en el proceso de delimitación del páramo de Santurban. La Corte interpretó el artículo 267 de la ley 1753 de $2015^{63}$ alejándose de la exégesis, al considerar que, para la delimitación del páramo, el MADS no solo debe tener en cuenta los criterios técnicos, ambientales, sociales y económicos de las corporaciones autónomas regionales junto con la cartografía provista por el Instituto de Investigación de Recursos Biológicos Alexander von Humboldt (IAVH), entidad que hace parte del SINA. Para la Corte, la potestad de las entidades para tomar decisiones con base en criterios técnicos no es absoluta. En cambio, al momento de delimitar los páramos y fijar el contenido de la resolución respectiva, el MADS debe observar cuatro aspectos: justicia distributiva; participación de las personas afectadas por su decisión; desarrollos sostenibles; garantía de la vigencia del principio de precaución64.

La participación ciudadana en materia ambiental irriga todo procedimiento que tenga la potencialidad de afectar de manera directa o indirecta los territorios locales. Más aún si la intervención pretende establecer el área que ha de ser considerada como páramo y que, por lo tanto, será objeto de especial protección legal. La jurisprudencia de la Corte indicó que el MADS al desarrollar el proceso de delimitación de los páramos, debe garantizar la participación de la comunidad y los límites que se establezcan deberán ser definidos por consensos con las diferentes poblaciones locales. En este punto ya se puede observar una aplicación directa del concepto de justicia ambiental, en tanto la jurisprudencia promueve una visión holística de la problemática ambiental, y aunque no habla aun expresamente de la necesaria interseccionalidad con los enfoques étnicos, de género, entre otros, que deben garantizar las decisiones administrativas, constituye un avance importante en el reconocimiento jurídicos de los derechos de las comunidades que habitan los páramos.

${ }^{62}$ Corte Constitucional de Colombia, sentencia T-361 de (2017c), mayo 30 de 2017.

${ }^{63}$ Ley 1753 de (2015).

${ }^{64}$ Corte Constitucional de Colombia, sentencia T-361 de (2017c), F.J. 15.3.1, mayo 30 de 2017. 
La Corte Constitucional en la sentencia T-361 de 201765, citó el argumento de Hofstede, el cual señala:

(...) se debe considerar que los límites sean definidos por un consenso de los diferentes grupos sociales, que la sociedad en su conjunto acepte que dentro de los límites hay un paisaje que merece un máximo cuidado y que su gestión reconozca la interrelación y dependencia del páramo con su entorno ${ }^{66}$.

Pese que la Corte ha construido una línea jurisprudencial en materia de participación ambiental a favor de las comunidades campesinas y locales, este reconocimiento no se plasmó en ningún planteamiento de la sentencia C-369 de (2019b) ${ }^{67}$, a través de la cual se juzgó la constitucionalidad de la ley 1930 de 201868 "Por medio de la cual se dictan disposiciones para la gestión integral de los páramos en Colombia". Si bien los cargos que presentó el actor se enmarcaban en un desconocimiento del Convenio 169 de la OIT $^{69}$, en particular del derecho de las comunidades indígenas a ser consultadas con anterioridad a la expedición de la ley 1930 de (2018), en ningún momento la Corte expresa que la situación planteada a favor de los pueblos indígenas o tribales sea equiparable a la posición de las comunidades campesinas, aun cuando estas tienen mayor población habitando los ecosistemas paramunos. Genera inquietud la posición de la Corte respecto a la participación de las comunidades campesinas en materia ambiental, especialmente porque en las audiencias públicas para decidir su constitucionalidad, líderes de las organizaciones campesinas reiteraron la necesidad de ser consultadas al momento de tomar decisiones sobre sus territorios ${ }^{70}$.

Para entrar en detalle en caso de estudio es necesario comenzar por la decisión judicial adoptada por el Tribunal Administrativo de Boyacá en el año (2018) ${ }^{71}$, al fallar una acción de tutela interpuesta por trabajadores mineros de las inmediaciones del páramo de Pisba, que se opusieron al proceso de delimitación de ese ecosistema, por considerar que los habían excluido. La sentencia reconoce la vinculatoriedad del precedente establecido en la Sentencia de Tutela 361 de $(2017 c)^{72}$, y va más allá, al señalar que así como otros entornos se han considerado como sujetos derechos por el valor y aporte que prestan para el sostenimiento de la especie humana y otras especies vivas, el páramo de Pisba como territorio que cumple con una función

\footnotetext{
65 Corte Constitucional de Colombia, sentencia T-361 de (2017c), F.J. 14.5, mayo 30 de 2017.

${ }^{66}$ Hofstede (2013), p. 122.

${ }^{67}$ Corte Constitucional de Colombia, sentencia C-369 de (2019b), agosto 14 de 2019.

${ }^{68}$ Ley 1930 de 2018.

${ }^{69}$ Organización Internacional del Trabajo, Convenio 169 (1989).

${ }^{70}$ Corte Constitucional de Colombia, Exp. D-12973, noviembre 06 de (2019a).

71 Tribunal Administrativo de Boyacá, Exp. 152383333002201800016 01, agosto 09 de 2018.

${ }^{72}$ Corte Constitucional de Colombia, sentencia T-361 de (2017c), mayo 30 de 2017.
} 
ecosistémica clave en el ciclo del agua tiene un derecho de protección autónoma. En ese sentido, retoma la jurisprudencia constitucional que consagra la naturaleza como sujeto de derecho planteada en el caso del Río Atrato, superando el antropocentrismo, aunque en una perspectiva que está más cerca aun del biocentrismo que del ecocentrismo, ya que el eje gravitacional del argumento con base en el cual se concede el amparo reposa en la protección de las personas que trabajan en la minería y de las familias, o sus generaciones futuras, que de ellos dependen.

El tribunal acogió el precedente de la sentencia T-606 de (2015a) ${ }^{73}$ y estableció que se debe garantizar la participación de la población en la delimitación de los páramos sin discriminación. El Tribunal de Boyacá consideró que los espacios de participación deben dar voz a todos los interesados como forma de garantizar la dignidad humana, tanto de quienes defienden intereses particulares, como colectivos. Con base en esto, expresó que lo intereses de los tutelantes, como mineros que podrían perder sus empleos, son legítimos de proteger en aras de salvaguardar la dignidad humana que les asiste; argumentó, que los procesos de participación de la comunidad se deben tornar en espacios de diálogo con la administración, a partir de los cuales todos los interesados puedan manifestar sus necesidades, incluyendo las de los trabajadores mineros, las cuales pueden ser previstas en futuras políticas públicas o con medidas de sustitución que ayuden en la inserción laboral en nuevas actividades económicas. De esa forma, el Tribunal propendió por el sostenimiento de las familias que dependen de la minería y que podrían verse afectadas por el proceso de delimitación del páramo. A su juicio, la intervención de la administración debe facilitar la protección de los derechos de las poblaciones más vulnerables, así como de los actores históricamente marginados y desprotegidos (2018) ${ }^{74}$.

Para el caso de estudio, como es la justicia ambiental en escenarios de ecosistemas de páramos y de extracción minera, es necesario observar el contexto en el que intervienen distintos actores locales, a partir de formas de lucha jurídicas, políticas y de facto, las cuales promueven una intervención ambiental sobre los recursos básicos para la subsistencia, como es el agua y el uso de la tierra a través de formas tradicionales y sustentables.

El contexto actual del páramo de Pisba le permite ser objeto de un análisis de justicia ambiental, por cuanto su ecosistema y sus espacialidades colindantes, son objeto de intervenciones institucionales y empresariales, es decir, lo que introducción se señaló como un territorio, escenario en el cual, además, se materializan desigualdades ambientales. Las

\footnotetext{
73 Tribunal Administrativo de Boyacá, Exp. 152383333002201800016 01, F.J 4.4. agosto 09 de 2018.

74 Tribunal Administrativo de Boyacá, Exp. 152383333002201800016 01, F.J 6.7 (i), agosto 09 de 2018.
} 
condiciones de vida de los habitantes del páramo Pisba y los municipios limítrofes han sido afectadas a causa de la explotación del páramo, principalmente a causa de la explotación del carbón. Esta actividad ha estado presente en la zona desde la década del 50 del siglo XX, tiempo en que se empieza a formar esta industria como fuente de energía para la siderúrgica de Paz del Río. Si bien desde inicios de ese siglo ya se daban las primeras extracciones de carbón destinado al uso doméstico, fue hasta después de mediados de ese siglo que la extracción del mineral se extendió con fines industriales. A partir de entonces y hasta ahora, es posible encontrar en municipios como Tasco, Socha y Paz del Río (Boyacá) tanto extracción artesanal como procesos industrializados de minería de carbón.

Desde el auge minero experimentado a partir de los años 60 en esta zona de Boyacá, comenzó un proceso simultáneo de abandono de la agricultura y olvido progresivo de las prácticas económicas tradicionales. De acuerdo con los relatos recogidos en la zona, antes era común encontrar cultivos de frijol, arveja y cebada. Hoy en día el cultivo predominante es la papa, con lo cual ha aumentado el uso de fungicidas y otros productos químicos necesarios para lo que ya hoy es prácticamente un monocultivo en esa región. En tal sentido, la expansión de la minería a lo largo de seis décadas promovió el abandono de actividades agrícolas, en desmedro de la autonomía alimentaria de los habitantes de la región y del deterioro de los suelos.

También las fuentes de agua han sido afectadas. El río Chicamocha es uno de los cuerpos de agua más importantes de la región. Actualmente este río presenta elevados niveles de contaminación debido a que recibe los residuos del proceso de extracción del carbón y de la industria siderúrgica, elevando a niveles de máxima alerta la presencia de metales pesados en sus aguas. Aunado a esto, la deforestación de sus laderas que se ha realizado con el fin de utilizar la madera para la construcción de las minas a socavón y el transporte del carbón, ha contribuido a la degradación del río.

Las cañadas y otros cuerpos de agua tributarios del río han desaparecido, como ocurre en la vereda El Banco, donde hace más de una década la siderúrgica Paz del Río adquirió predios con el fin de adelantar actividades de extracción de hierro mediante minería a cielo abierto. En esta vereda del municipio de Tasco, la empresa levantó la capa vegetal a un metro y medio de profundidad en una extensión equivalente a dos campos de futbol y taló los arboles de aproximadamente 30 metros a la redonda. Luego de ello, y sin explicación, cesó la actividad sin efectuar ningún tipo de reparación de la zona afectada, dejando expuesta la capa de suelo mineral, lo que hace que las pocas lluvias que allí caen no alcancen a penetrar el suelo 
aumentando la erosión y causando la desaparición de las quebradas que atravesaban esta zona; aguas de las cuales dependían las familias vecinas para algunas de sus actividades domésticas, así como la irrigación de sus cultivos y los bebederos de sus animales. Hasta el día de hoy está en curso una acción popular en contra de la empresa Paz del Río por estos hechos sin que se haya reparado aun el deterioro ambiental ocasionado.

Otro ejemplo de las afectaciones generadas por la minería en la región se encuentra en la vereda Hormezaque del municipio de Tasco. Allí se ocasionó un derrumbe en el año 2003 que afectó más de 10 hectáreas de suelos productivos, lo que obligó a las familias habitantes de la zona a abandonar sus predios luego de la pérdida de sus viviendas, enceres y cultivos; hoy estas tierras no son aptas para la edificación ni para la siembra o el pastoreo a causa de la erosión y la inestabilidad que aun presentan.

Esta remoción de tierras en masa fue consecuencia de la extracción indiscriminada del carbón de la mina a socavón La Chapa, que se instaló en esta vereda desde los años 70. Hoy en día las instalaciones se encuentran abandonadas tras el derrumbe cuyas afectaciones aun no han sido reparadas por la empresa Paz del Río.

La minería no solo ha ocasionado deterioro ambiental. La disminución de la agricultura es otra consecuencia negativa del extractivismo en los municipios que integran el páramo de Pisba. La minería ha generado una cultura de "dinero rápido". Un trabajador de este sector se puede ganar el equivalente a US\$ 500 en un solo mes, mientras que en las actividades de cultivo con dificultad sobrepasaría los US\$300. Desde mediados de siglo XX, cuando la minería comenzó a atraer mano de obra, muchas familias comenzaron a depender de esta actividad, abandonando las formas económicas tradicionales relacionadas con los cultivos de alimentos como la arveja, el frijol, el trigo, la papa, entre otros. Aquellos que lograban alcanzar un capital con la minería, luego de eso consideraban las actividades agrícolas como lentas, costosas, pesadas e improductivas, motivo por el cual preferían invertir sus recursos en compra de unas pocas cabezas de ganado vacuno, y los que más capital alcanzaban, lo invertían en vehículos para el transporte colectivo de pasajeros o de carga, que luego colocaban al servicio de la misma actividad minera en la región. Con esto se ha incrementado la carga ambiental del territorio, pues mucho del ganado adquirido ha sido ubicado en las zonas del borde del páramo o dentro de él, y las vías terrestres se han deteriorado más, lo que ha elevado los costos de transporte para los agricultores, ha aumentado la contaminación por la aspersión del polvo y tierra sobre casas y cultivos, así como el deterioro de las viviendas aledañas a las vías por efecto de la vibración 
ocasionada al paso de los vehículos pesados. Todo esto genera un círculo vicioso que empuja a los habitantes de municipios como Tasco, Socha y otros que comparten el páramo, a dedicarse a la minería y la pequeña ganadería, antes que a la agricultura.

En la última década han llegado nuevos actores transnacionales al territorio, como la minera canadiense Hunza Coal, que obtiene las licencias de operación a final del año 2009. Esta empresa obtuvo las licencias de operación minera mediante las resoluciones de la Gobernación de Boyacá № 1863, 1864 y 1865, del día 30 de diciembre de 2009. Desde su llegada, la sola promesa de generación de puestos de trabajo con ingresos más elevados del promedio general registrado en el municipio generó un proceso inflacionario en los costos de la canasta básica, como los arriendos, alimentos y transporte, mermando así las condiciones económicas de la población en general.

Estas intervenciones repercuten de forma definitiva en el paisaje, dado que el páramo de Pisba y los municipios vecinos, sufren las prácticas de la minería, la cual acaba con la fauna y flora de la región, además de derivar en planos desoladores. La transformación de los espacios donde prevalecía la vida en paisajes devastados, fruto de intervenciones agresivas que destruyen los escenarios locales y generan imaginarios colectivos que transforman las identidades campesinas en el deseo de una subjetividad obrera, que paradójicamente tampoco se alcanza, pues el minero queda a la deriva entre lo que fue su origen campesino y una condición de obrero incompleto, por cuanto no se ve realmente beneficiado de la modernidad que prometía traer la minería.

Las desigualdades ambientales que más preocupan a los campesinos locales se presentan con los efectos que el desarrollo de la minería ha tenido sobre las fuentes hídricas, que tienen su origen en el páramo. Del agua en la explotación minera en el páramo de Pisba, se hace un uso ingente para lograr la explotación de los minerales, agua que después recoge todos los residuos químicos, muchos de ellos tóxicos, contaminando con metales pesados las nuevas corrientes de agua y la tierra sobre la que transita o reposa ${ }^{75}$. A lo anterior se debe sumar, que muchas de las prácticas de las multinacionales, no prevén una disposición correcta de los residuos, lo que lleva a que la mayor de las veces, sean las fuentes hídricas la solución más rápida y sencilla para deshacerse de estos.

${ }^{75}$ Ilsa (2014), pp. 40-41. 
Respecto a esto, los campesinos de la región consideran lesionados sus derechos ambientales, en cuanto consideran que son sus recursos hídricos los que se ven afectados y comprometidos. Entre 28 y 32 nacimientos de agua se han perdido por la intervención de empresas multinacionales y nacionales en su territorio ${ }^{76}$. La preocupación porque este tipo de actuaciones empresariales puede dejar a esta población sin fuentes hídricas ha sido conocida en todo el país.

Lo anterior se hace más grave si se considera la entrega de títulos mineros a favor de la multinacional Hunza Coal por encima de los 2800 metros sobre el nivel del mar, aun cuando para la fecha de entrega, los territorios sobre este nivel del mar ya eran considerados zona de páramos conforme a la ley77.

El desarrollo de la minería tiene efectos nocivos sobre las tierras y el aire de la zona; el primero de ellos porque la extracción de los minerales exige una remoción considerable de tierra y uso de materias tóxicas al ecosistema y sus fuentes hídricas, como lo presenta el informe de ILSA $^{78}$, el cual indica que la obtención de un kilogramo de cobre exige el uso de cerca de $349 \mathrm{~kg}$ de materia y para el caso del oro es aún peor, exigiendo el uso de $540 \mathrm{~kg}$ de materia aproximadamente. A esto se le debe agregar los niveles de deforestación, los cuales se producen para acceder a los espacios de extracción, lo que termina afectando la flora y fauna, así como debilitando la montaña y causando deslizamientos y aludes ${ }^{79}$. La contaminación del aire es otra consecuencia derivada de la minería, ya sea por el proceso de extracción de los minerales o en la etapa de la cadena de consolidación del mineral para su exportación.

A partir de los hechos descritos se evidencia la ausencia de justicia ambiental en el territorio del páramo de Pisba. Las afectaciones a este ecosistema de vital importancia en la generación del agua, vulneran derechos fundamentales como el consagrado en el artículo 79 constitucional, en tanto se transgrede el derecho a gozar de un ambiente sano y el consecuente deber estatal de proteger la diversidad e integridad del ambiente y conservar las áreas de especial importancia ecológica, como en este caso lo es el páramo.

Se puede además hablar de injusticia ambiental en tanto las comunidades han sido sistemática desconocidas por las autoridades administrativas ambientales en diferentes ocasiones durante las últimas dos décadas. Las más ostentosas se remiten a la primera década

\footnotetext{
${ }^{76}$ Caracol Tunja (2016).

77 Ilsa (2014), p. 31.

${ }_{78}$ Ídem, p. 39.

79 Ídem, p. 39.
} 
del siglo, cuando en un proceso irregular y extraordinariamente ágil se otorgaron licencias de explotación a la minera canadiense Hunza Coal para la extracción del carbón en zona histórica, ambiental y culturalmente comprendida dentro del páramo de Pisba. Esta actuación vulnera el debido proceso ambiental, pero además la obligación estatal de proteger un ecosistema tan frágil e importante como es el páramo.

Entonces, las comunidades no fueron consultadas, lo que constituyó una violación al principio de participación de las comunidades campesinas de la zona en las decisiones que las afectan. Solo a través de la movilización social fue posible la expulsión de la empresa Hunza Coal del territorio del páramo de Pisba $^{80}$.

Luego de las vías de hecho a las que se vieron obligadas las poblaciones campesinas de Pisba como consecuencia de la negligencia estatal en el otorgamiento de las licencias para la minera, sobrevino una discusión amplia en ese territorio acerca de la necesidad de proteger el páramo, entre otras, a través de acciones constitucionales que pusieran freno a los actos de injusticia ambiental cometidos por la administración local y el descuido del gobierno nacional. Si bien las acciones constitucionales han generado espacios institucionales para la discusión de los procesos de licenciamiento ambiental, resultan insuficientes para remediar, o al menos mitigar, el impacto causado por la minería en Pisba.

Si una condición de las injusticias ambientales, como se expuso en el primer apartado, es que se produce en un contexto histórico de daño sobre los ecosistemas, las comunidades y sus culturas, el caso de Pisba confirma la teoría. El daño sobre el páramo, los cuerpos de agua, el aire, las tradiciones culturales y las formas de economía locales, se ha generado tras siete décadas de explotación del carbón y del hierro. No ha sido suficiente en este caso la acción constitucional interpuesta contra la empresa que explota la mina de hierro a cielo abierto en la vereda El Banco del municipio de Tasco, pues si bien se detuvo el proceso de extracción, el daño ambiental no se ha remediado, dado que sigue expuesta la capa mineral luego del levantamiento del manto vegetal que hace años efectuó la empresa Paz del Río.

Otro tanto ocurre con en el caso de la vereda La Chapa, donde luego del deslizamiento de tierra causado por la extracción indiscriminada de carbón a socavón por parte de la empresa Paz

\footnotetext{
80 Se han interpuesto acciones populares (2006- 00116,10 de mayo de 2005; 2013-00149, 28 de enero de 2013) en contra del desarrollo minero en el páramo de Pisba, las cuales han buscado velar por el interés colectivo de la población y del páramo de Pisba, sin embargo, algunas de estas han sido desestimadas por los despachos judiciales. Campaña Páramos Greenpeace Colombia (2015), pp. 24-28.
} 
del Río, se produjo la pérdida de hectáreas de cultivo y de viviendas, daños que aun no han sido reparados integralmente a los habitantes, mientras que los suelos que antiguamente usufructuaban están lejos de recuperarse para el cultivo, la construcción o la ganadería. Este daño ha afectado los derechos ambientales, así como la soberanía alimentaria, el derecho a una vivienda digna consagrado en el artículo 25 de la Declaración Universal de Derechos Humanos, en el artículo 11 del Pacto Internacional de Derechos Económicos, Sociales y Culturales y en el artículo 51 de la Constitución colombiana.

La imposibilidad de las comunidades afectadas de continuar con sus prácticas culturales y económicas tradicionales, afecta el derecho constitucional reconocido en el artículo 7 acerca de la diversidad cultural y el artículo 70 que establece la diversidad cultural como fundamento de la nación, dada la estrecha relación que existe entre las formas tradicionales de sustento, cultivo, alimentación y trabajo, como expresiones culturales de un pueblo. También se ve afectado el derecho de estas comunidades consagrado en el artículo 65 constitucional, dado que se trunca el desarrollo integral de las actividades agrícolas, el uso y adecuación de tierras productivas.

Como se expuso en su momento, la noción de justicia ambiental presente en la literatura revisada en el primer apartado y que ha sido recogida por la jurisprudencia de la Corte Constitucional colombiana, está integrada por dos elementos: el reparto equitativo de cargas y beneficios fundado en el principio constitucional de equidad ambiental; y de otro lado, una demanda de justicia participativa, principalmente de aquellos que se consideran o son efectivamente afectados.

En el caso de Pisba las cargas asumidas por la población campesina como consecuencia del deterioro ambiental ocasionado por la minería no han contribuido a una mejora efectiva de las condiciones de vida en el territorio. La calidad y cantidad de las aguas se ha disminuido, las vías de transporte terrestre necesarias para el transporte de personas y la comercialización de los pocos productos que aun se cultivan sigue siendo un obstáculo para la población que dependen de los cultivos, al tiempo que mantiene elevados los precios de alimentos e insumos que llegan de otras zonas del país. Las regalías producto de la exportación del carbón de esta zona no se reflejan en más instituciones educativas, de salud ni en infraestructura de servicios públicos.

En cuanto al segundo elemento, la situación de justicia ambiental no es mejor. La ausencia de mecanismos de participación efectiva de las comunidades campesinas en el páramo de Pisba ha obligado a que estas acudan a las vías de hecho para detener los proyectos extractivistas en el 
territorio. Lo hicieron frente a la empresa Hunza Coal y lo están haciendo nuevamente ante la inminente concesión de licencias de explotación a favor de la empresa de minería e hidrocarburos Maurel y Prom81. Esto es sumamente relevante en este análisis para demostrar la ausencia de justicia ambiental y la relación compleja que se teje entre esa perspectiva teórica y sus aplicaciones judiciales. Estos son los hechos: en el 2018 el Tribunal de Boyacá ordenó a la empresa Maurel y Prom garantizar espacios de concertación y participación con las comunidades de la provincia de Sugamuxi, vecina de la provincia de Valderrama, luego de que en la audiencia pública realizada en el municipio de Pesca el 6 de noviembre de 2016 las comunidades se opusieran a la explotación de hidrocarburos en el territorio. Maurel y Prom comenzó desde entonces a buscar nuevas zonas donde ejercer su actividad extractivista sin oposición popular, lo que la llevó a solicitar ante la Autoridad Nacional de Licencias Ambientales (ANLA) en octubre de 2019 licencia ambiental para el proyecto "ÁREA DE PERFORACION EXPLORATORIA COR-15", localizado en los municipios de Beteitiva, Busbanza, Corrales y Tasco en el departamento de Boyacá. El 21 de julio de 2020 la Asociación de Acueductos Comunitarios de Tasco, el Instituto Latinoamericano para una Sociedad y un Derecho Alternativos (ILSA), la Corporación Greenpeace Colombia, la Corporación de servicio a proyectos de desarrollo (PODION), la Corporación Guamán Poma y el Personero Municipal de Tasco, solicitaron ante la ANLA la realización de una audiencia pública en el marco del proceso de licenciamiento ambiental, solicitud que también fue elevada por CORPOBOYACA unos días después. Como resultado de la solicitud, la ANLA, expidió el auto № 10578 de 3 de noviembre de $2020^{82}$, a través del cual cita a audiencia pública para el 18 de diciembre de 2020.

Mientras que la empresa ha tenido conocimiento desde octubre de 2019 de todas las actuaciones administrativas adelantadas ante la ANLA, y lleva varios años preparando los argumentos y las pruebas para defender su solicitud de licenciamiento ambiental, las comunidades campesinas y organizaciones civiles deben prepararse en unos pocos días para intervenir en una audiencia pública que se llevaría a cabo en medio de una crisis sanitaria global. Con las medidas de distanciamiento social y limitación en el aforo de espacios públicos, es imposible otorgar garantías para que la comunidad pueda participar en una audiencia pública donde su voz pueda ser expresada de manera segura y clara. La convocatoria a la audiencia solicitada por la comunidad responde a la exigencia legal, pero lo hace sin las condiciones necesarias para garantizar la participación efectiva y eficaz de la comunidad en material

81 [Disponible en: https://bit.ly/3C6yjLZ].

82 [Disponible en: https://bit.ly/3quPq7X]. 
ambiental, lo que una vez más ubica el caso del páramo de Pisba como un lamentable ejemplo de injusticia ambiental.

\section{Conclusiones}

Las discusiones sobre justicia ambiental y lo que pueden representar para las comunidades se hacen más significativas si estas logran emerger de la teoría a un ejercicio que redunde en las modificaciones reales de las condiciones de desigualdad ambiental a las que se han visto sometidos las poblaciones más vulnerables.

Los procesos y formas a partir de las cuales se buscan lograr escenarios más justos han comenzado por dar una mayor relevancia a los actores que sufren dichas marginalidades, son estos quienes han retomado las reivindicaciones y denuncias ambientales.

Las poblaciones campesinas han logrado organizarse para intervenir en materia ambiental, manifestándose en contra de megaproyectos como los de Cajamarca ${ }^{83}$, nordeste antioqueño ${ }^{84}$, el páramo de Santurban, Cumaral, entre otros. Las comunidades campesinas tienen el derecho de participar en las decisiones que afectan sus formas de subsistencia, sus concepciones de desarrollo y los espacios que habitan. Con el objeto de desvelar y revertir en sus escenarios las desigualdades ambientales, han asumido un papel más activo en las discusiones de los proyectos industriales, mineros, viales, turísticos entre otros, lo que ha conducido a muchas de sus organizaciones a repensar las formas de intervenir, resistir y modificar las políticas de daño ambiental que surgen desde el Estado o bajo su amparo.

Los campesinos que habitan el páramo de Pisba sufren estas desigualdades, pero a través de acciones de hecho, jurídicas y políticas han comenzado a asumir un papel clave para reversar tal situación. Aquí la ley y la jurisprudencia, como se presentó, han sido motores claves para que poblaciones locales, como las campesinas, sean escuchadas al momento de tomar decisiones que involucran sus territorios; no obstante, los procesos de consulta se han quedado en la ritualidad jurídica y poca trascendencia ha tenido la voz de los campesinos en esos espacios, lo que aumenta los escenarios de injusticia ambiental.

${ }^{83}$ Sánchez (2014).

${ }^{84}$ Quiroga (2014). 
Algunos procesos locales impulsados por los campesinos en el páramo de Pisba, han producido acciones de hecho que han derivado en la expulsión de empresas mineras por las afectaciones a sus recursos naturales; y lo que es más interesante aun, han despertado la solidaridad de los pobladores de otras comunidades, de los movimientos estudiantiles, incluso del movimiento obrero, como se demostró en los hechos que llevaron a la expulsión en el territorio de la empresa Hunza Coal del páramo de Pisba. Sin embargo, las expulsiones se han presentado en un marco del retiro de las licencias para seguir operando o por el abandono de la operación, pero no se materializan en condenas por parte de las instituciones estatales por el pasivo ambiental que las empresas han generado.

La búsqueda de los campesinos por superar las desigualdades ambientales, en el mejor de los casos termina por reconocerlos como actores legítimos para intervenir el páramo y sus territorios aledaños, sin embargo, al mismo tiempo les impone la carga de ser los llamados a recuperar los territorios devastados, carga que es asumida por ellos con el objetivo evitar un mayor daño a sus territorios, pero que de forma paradójica los mantiene en escenarios de injusticia ambiental. Esto ha provocado que sus luchas terminen limitadas al propósito de expulsar a las empresas extractivistas del territorio, aplazando la recuperación ambiental mediante actividades sustentables y enfrascándolos en pugnas internas por el poder político y la visibilidad que también genera el liderazgo campesino. Esta consecuencia amerita una reflexión mas detenida, pues ha sido poco analizada por los estudios de justicia ambiental actualmente disponibles.

\section{Bibliografía citada}

Agyeman, Julian; Bullard, Robert y Evans, Bob (2002): “Exploring the Nexus: Bringing Together Sustainability, Environmental Justice and Equity", en Space and Polity (6, 1), pp. 77-90.

Arriaga, Alicia (2010): "La construcción de la justicia ambiental en Europa y los EE. UU.: Diferencias y Similitudes", X Congreso Español de Sociología. Pamplona, pp. 01-15.

Barbalace, Roberta (2001): "Environmental Justice and the NIMBY Principle". [Disponible en: https://bit.ly/3F5JS8b]. [Fecha de consulta: 13 de noviembre de 2019]. 
Bellmont, Yary (2012): "el concepto de justicia ambiental: reflexiones en torno a la jurisprudencia constitucional colombiana del siglo XXI". Universidad Nacional de Colombia. Bogotá, pp. 01-160.

Campos, Milagros; Toscana, Alejandra y Campos, Juan (2015): “Riesgos socionaturales: Vulnerabilidad socioeconómica, justicia ambiental y justicia espacial”, en Cuadernos de Geografía: Revista Colombiana de Geografía $(24,2)$, pp. 53-69.

Cañola, Mayra y Palacio. Simón. (2019): “Proyecto Hidroeléctrica Ituango: una disputa por el territorio", en Kogoró: Revista de Estudiantes de Antropología (№ 9), pp. 38-55.

Caracol Tunja (2016): “Campesinos protestan hace más de un año en el páramo de pisba contra la explotación minera". Caracol Radio. [Disponible en: https://bit.ly/30kP6hm]. [Fecha de consulta 16 de octubre de 2019].

Carruthers, David. (2008): "Introduction: Popular Environmentalism and Social Justice in Latin America”, en David Carruthers (ed.). Environmental Justice in Latin America. Problems, Promise, and Practice (London, The MIT Press) pp. 01-22.

Commission For Racial Justice (1987): “Toxic Wastes and Race in The United States A National Report on the Racial and Socio-Economic Characteristics of Communities with Hazardous Waste Sites" New York, pp. 01-10.

Cotton, Matthew (2017): "Fair Fracking? Ethics and Environmental Justice in United Kingdom Shale Gas Policy and Planning", en Local Environment (22, 2), pp. 185-202.

Cruells, Marta (2015): “La interseccionalidad política: tipos y factores de entrada en la agenda política, jurídica y de los movimientos sociales" (Universitat Autònoma de Barcelona, Barcelona), pp. 01-176.

Diario Digital La Piragua (2018): "Sector minero optimista con fallo de la corte sobre caso Cumaral” Diario La Piragua. [Disponible en: https://bit.ly/3kx3jyV]. [Fecha de consulta 05 de junio de 2019].

Dichiro, Giovanna (1999): “La justicia social y la justicia ambiental en los Estados Unidos: La naturaleza como comunidad”, en Ecología Política (№ 17), pp. 105-18. 
JUSTICIA AMBIENTAL Y JURISPRUDENCIA CONSTITUCIONAL: EL CASO DE LAS DESIGUALDADES AMBIENTALES EN EL PÁRAMO DE PISBA

Freudenberg, Nicholas y Steinsapir, Carol (1991): "Not in Our Backyards: The Grassroots Environmental Movement", en Society and Natural Resources (4, 3), pp. 235-45.

Hofstede, Robert (2013): “Lo mucho que sabemos del páramo. apuntes sobre el conocimiento actual de la integridad, la transformación y la conservación del páramo”, en J. Cortés-Duque y C. Sarmiento (eds.). Visión socioecosistémica de los páramos y la alta montaña colombiana: memorias del proceso de definición de criterios para la delimitación de páramos (Bogotá, Instituto de Investigación de Recursos Biológicos Alexander von Humboldt), pp. 113-25.

ICANH (2017): “Elementos para la conceptualización de lo 'campesino’ en Colombia” (Bogotá, Ministerio de Cultura, No data) pp. 01-12.

ILSA (2014): "El paramo de pisba en tasco resistencia campesina frente a la gran minería" Bogotá, pp. 01-62.

Jessup, Brad (2018): “Trajectories of Environmental Justice: From Histories to Futures and the Victorian Environmental Justice Agenda", en Victoria University Law and Justice Journal $(7,1)$, pp. 48-65.

Lefebvre, Henri (2013): La producción del espacio (Traducc. Emilio Martínez, Madrid, Capitán Swing Libros, S. L.).

Lessenich, Stephan (2019): La sociedad de la externalización (Alberto Ciria, Barcelona, Herder Editorial).

Martínez-Alier, Joan (2002): The Environmentalism of the Poor A Study of Ecological Conflicts and Valuation (Northampton, Edward Elgar Publishing Limited).

(2008): “Conflictos ecológicos y justicia ambiental”, en Papeles (№103), pp. 11-28.

Méndez, Olga (2013): "La Colosa, entre los flujos del gran capital y la tradición del suelo fértil”, editado por G. Delgado Ramos, en Ecología política del extractivismo en América Latina: Casos de resistencia y justicia socioambiental (Buenos Aires, CLACSO), pp. 211-232.

Mesa, Gregorio (2010): “¡Quince años no es nada! Historia actual de la política y la legislación ambiental en Colombia", editado por Catalina Toro and B. Marquardt, en Quince Años de La Política Ambiental En Colombia (Bogotá, UNIJUS), pp. 05-14. 
Ojeda, Diana (2016): "Los paisajes del despojo: propuestas para un análisis desde las reconfiguraciones socioespaciales", en Revista Colombiana de Antropología (52, 2), pp. 1943.

Piñeros, Robinson (2016): “La territorialización del agronegocio de la palma de aceite y la caña de azúcar en la altillanura colombiana. Aportes para el estudio de sus efectos a las condiciones de trabajo de los asalariados rurales", VIII Congreso Latinoamericano de Estudios del Trabajo, Buenos Aires, pp. 01-20.

Quiroga, Catalina (2014): Hacia un territorio minero-campesino: propuestas territoriales desde el movimiento socioterritorial en el nordeste de Antioquia, Colombia. Editado por Barbara Göbel y Astrid Ulloa, en Extractivismo Minero En Colombia y América Latina (Bogotá, Universidad Nacional de Colombia, Facultad de Ciencias Humanas), pp. 347-385.

Ramírez, Sonia; Galindo, María y Contreras, Carlos (2015): “Justicia ambiental: Entre la utopía y la realidad social", en Culturales $(3,1)$, pp. 225-50.

Rees, W. (2009): “Naturaleza humana, huella ecológica e injusticia ambiental”, en Cuaderno Interdisciplinar de Desarrollo Sostenible (№3), pp. 3-28.

Reichmann, Jorge (2003): “Tres principios básicos de justicia ambiental”, en Revista Internacional de Filosofía Política (21), pp. 103-20.

Rojas, Juan (2016): “Transformaciones ambientales generadas por la expansión del cultivo de palma de aceite (Elaeis Guineensis) en el departamento del Meta" Universidad Nacional de Colombia, Bogotá, pp. 01-106

Romero, Hugo (2009): “Comodificación, exclusión y falta de justicia ambiental”, editado por Ovidio Delgado y Hellen Cristancho, en Globalización y territorio: reflexiones geográficas en América Latina (Bogotá, Universidad Nacional de Colombia), pp. 243-291.

Sabogal, Julian (2013): “La Colosa, entre los flujos del gran capital y la tradición del suelo fértil” editado por G. Delgado Ramos, en Ecología Política Del Extractivismo En América Latina: Casos de Resistencia y Justicia Socioambiental (Buenos Aires, CLACSO), pp. 171-191.

Sánchez, Diana (2014): “El conflicto por la producción del territorio en el caso del proyecto minero La Colosa, Tolima, Colombia”, Barbara Göbel y Astrid Ulloa (ed.), Extractivismo 
JUSTICIA AMBIENTAL Y JURISPRUDENCIA CONSTITUCIONAL: EL CASO DE LAS DESIGUALDADES AMBIENTALES EN EL PÁRAMO DE PISBA

Minero En Colombia y América Latina (Bogotá, Universidad Nacional de Colombia, Facultad de Ciencias Humanas) pp. 347-385.

Soja, Edward (1996): “Thirdspace Journeys to Los Angeles and Other Real-and-Imagine Places” (Cambridge, Blackwell Publisher).

Torres, Maria (2013): “Análisis de nuevas dinámicas territoriales por proyectos de infraestructura y su influencia en la generación de conflictos socio ambientales. caso de estudio: Hidroituango" (Universidad Nacional de Colombia, Medellín), pp. 01-174.

Valenzuela, Claudia (2018): "Ética de la tierra y justicia ambiental: Reflexiones en torno a la responsabilidad del ser humano en el devenir actual, desde un enfoque social y filosófico", en Atenea (Concepción) (№ 517), pp. 167-80.

\section{Normas jurídicas citadas}

Constitución Política de Colombia de 1991. Gaceta Constitucional No 116, 20 de julio de 1991.

Ley 1753 de 2015: Por La Cual Se Expide El Plan Nacional de Desarrollo 2014-2018 'Todos Por Un Nuevo País', Diario Oficial (49538), junio 09 de 2015.

Ley 1930 de 2018: por medio de la cual se dictan disposiciones para la gestión integral de los páramos en Colombia, Diario Oficial (50.667), julio 27 de 2018.

Declaración sobre los derechos de los campesinos y de otras personas que trabajan en las zonas rurales, Consejo de Derechos Humanos, United Nations Documents (A/C.3/73/L.30), 28 de noviembre 2018.

Convenio sobre el acceso a la información, la participación del público en la toma de decisiones y el acceso a la justicia en materia de medio ambiente, "Convenio de Aarhus", Comisión Económica para Europa: Comité de Política Ambiental, 25 de junio 1998.

Convenio Sobre Poblaciones Indígenas y Tribales, 1989 (Conv. Núm. 169) Organización Internacional del Trabajo, 27 de junio 1989.

Convenio Sobre Poblaciones Indígenas y Tribales (Conv. Núm. 107) Organización Internacional del Trabajo, 26 de junio 1957. 
Boletín No. 44, Secretaría General y Jurídica de Boyacá “CORPOBOYACÁ.”, Boletín Oficial CORPOBOYACÁ, enero 2010.

\section{Jurisprudencia citada}

Corte Constitucional de Colombia: Sentencia T-411 de 1992 (17 de junio). M.P. Alejandro Martinez Caballero.

Corte Constitucional de Colombia: Sentencia C-593 de 1995 (07 de diciembre). M.P. Fabio Moron Diaz.

Corte Constitucional de Colombia: Sentencia C-535 de 1996a (16 de octubre). M.P.Alejandro Martinez Caballero.

Corte Constitucional de Colombia: Sentencia T-574 de 1996b (29 de octubre). M.P. Alejandro Martínez Caballero.

Corte Constitucional de Colombia: Sentencia C-293 de 2002 (23 de abril). M.P Alfredo Beltrán Sierra.

Corte Constitucional de Colombia: Sentencia T-348 de 2012 (15 de mayo). M.P. Jorge Pretelt Chaljub.

Corte Constitucional de Colombia: Sentencia T-135 de 2013 (13 de marzo). M.P. Iván Palacio Palacio.

Corte Constitucional de Colombia: Sentencia C-123 de 2014a (05 de marzo). M.P. Alberto Rojas Ríos.

Corte Constitucional de Colombia: Sentencia T-294 de 2014b (22 de mayo). M.P. María Victoria Calle Correa.

Corte Constitucional de Colombia: Sentencia T-606 de 2015a (21 de septiembre). M.P. Jorge Iván Palacio Palacio.

Corte Constitucional de Colombia: Sentencia T-660 de 2015b (23 de octubre). M.P. Jorge Ignacio Pretelt Chaljub. 
Corte Constitucional de Colombia: Sentencia C-035 de 2016a (08 de febrero). M.P. Gloria Stella Ortiz.

Corte Constitucional de Colombia: Sentencia T-622 de 2016 (10 de noviembre). M.P. Jorge Iván Palacio Palacio.

Corte Constitucional de Colombia: Sentencia C-389 de 2016b (27 de julio). M.P María Victoria Calle Correa.

Corte Constitucional de Colombia: Sentencia T-445 de 2016c (19 de agosto). M.P. Jorge Iván Palacio Palacio.

Corte Constitucional de Colombia: Sentencia T-622 de 2016d (10 de noviembre). M.P. Jorge Iván Palacio Palacio.

Corte Constitucional de Colombia: Sentencia SU-133 de 2017a (28 de febrero). M.P. Luis Ernesto Vargas Silva.

Corte Constitucional de Colombia: Sentencia SU-217 de 2017b (18 de abril). M.P. María Victoria Calle Correa.

Corte Constitucional de Colombia: Sentencia T-361 de 2017c (30 de mayo). M.P. Alberto Rojas Ríos.

Corte Constitucional de Colombia: Sentencia SU-095 de 2018 (11 de octubre). M.P Cristina Pardo Schlesinger.

Corte Constitucional de Colombia: Audiencia Pública Sobre La Ley de Páramos. Ex. D-12973. 2019. (06 de noviembre).

Corte Constitucional de Colombia: Sentencia C-369 de 2019b (14 de agosto). M.P. Cristina Pardo Schlesinger

Corte Suprema de Justicia: Sala de Casación Penal, Sala de No.03, “STP 2028-2018” (Radicado № 96414). M.P. José Francisco Acuña Vizcaya. 2018. (13 de febrero).

Tribunal Administrativo de Boyacá: Sala de Decisión No. 03. Tutela Exp. 1523833330022018 00016 01. M.P. Clara Elisa Cifuentes Ortiz. 2018. (09 de agosto). 